\title{
DETECTION OF AFLATOXINS IN UHT AND POWDERED FLAVORED MILK
}

\author{
ZEINAB M. ABDEL-HAMEED ${ }^{1}$; MARWA M.N. EL-GENDI ${ }^{1}$ and NOHA H. ORABY ${ }^{2}$ \\ ${ }^{1}$ Food Hygiene Department, Animal Health Research Institute, Agriculture Research Center (ARC), Assiut Regional Lab. \\ ${ }^{2}$ Mycology Department, Animal Health Research Institute, Agriculture Research Center (ARC), El-Dokii, Giza
}

Received: 15 May 2019; Accepted: 7 July 2019

\begin{abstract}
In this study, a total of 150 random samples of flavored milk ( 75 for UHT and 75 for powdered form) including banana, strawberry and chocolate (25 samples each) were collected from different dairy shops and supermarkets in Assiut city, Egypt. The samples were evaluated mycologically, in addition to aflatoxins detection using thin layer chromatography (TLC) and enzyme-linked immunosorbent assay (ELISA). The obtained results showed that 33.33 and $49.33 \%$ of the examined UHT and powdered milk samples contained molds, respectively; with average counts of 28.33 and $56.67 \mathrm{cfu} / \mathrm{g}$, respectively. The most isolated molds were Aspergillus species, followed by Pencillium species then Alternarea species and Cladosporium species. Regarding the aflatoxins production, 2 out of $5(40 \%)$ and 8 out of $16(50 \%)$ of A. flavus strains produced variable levels of aflatoxins that were isolated from the examined UHT and powdered milk samples, respectively. The toxogenic A. flavus strains produced AFB1 and AFB2 with mean values of $0.88 \pm 0.13$ and $1.2 \pm 0.18 \mathrm{ppb}$, respectively. The mean concentrations of AFM1 in the examined UHT and powdered milk samples were $2.01 \pm 0.02$ and $1.72 \pm 0.28 \mathrm{ppt}$, respectively; and these estimated levels were above the permitted level of the Egyptian standard regulations and below the tolerated levels of the European countries. The public health hazard of aflatoxins was discussed.
\end{abstract}

Key words: Flavored milk, molds, aflatoxins.

\section{INTRODUCTION}

Fungal spoilage of dairy foods is frequent and a matter of concern for human health as they continues to be a major challenge for industrials and, in modern practices, both preventive and control approaches are usually combined to reduce its incidence.

The fungal contamination of heat treated and processed milk depends on the practices followed in the production, formulation, processing, packaging, storage, distribution and handling (Pal, 2014). Furthermore, mold spoilage may be attributed to airborne fungi as fungal spores which are easily dispersed into the dairy plant air (Kure et al., 2004). Moreover, some fruit preparations used in manufacturing of flavored milk reported to contain heat-resistant ascospore-forming fungi (Suriyarachchi and Fleet., 1981).

Many genera of molds growing on agricultural products produce toxic substances, generally called mycotoxins; some have mutagenic or carcinogenic

Corresponding author: Dr. MARWA M.N. EL-GENDI

E-mail address: ahmednofel125@yahoo.com

Present address: Food Hygiene Department, Animal Health Research Institute, Agriculture Research Center (ARC), Assiut Regional Lab. effects; others are toxic for specific organs (Bezerra da Rocha et al., 2014). Mycotoxins were defined as secondary metabolites of various different fungal species and they differ in chemical structure, biosynthetic origins, and biological effects. Clinicians classify mycotoxins as hepatotoxins, nephrotoxins, neurotoxins, immunotoxins (Bennett and Klich, 2003).

Aflatoxins (AFs) are mycotoxins produced by some species of Aspergillus particularly A. flavus and $A$. parasiticus (Creppy, 2002). It was estimated that about 1-3 to $6 \%$ of AFB1 in feed is present as AFM1 in milk from within a few hours after ingestion of contaminated meal up to 2 days after suspension of feeding the diet (Gürbay et al., 2006). From the global perspective of toxicity profiling, the accurate detection of AFs in milk is a mandatory task for regulatory and health purposes.

The permitted level of AFM1 in milk and dairy products was strictly regulated in the developed countries; the regulatory limit for AFM1 was $50 \mathrm{ppt}$ in European countries, while a more restrictive limit $25 \mathrm{ppt}$ for milk intended for consumption by nursing infants and children was fixed (Codex Alimentarius Commissions, 2001). While, according the standard of the Egyptian regulations (1990), no permissible limits were allowed for AFM1 as it should be at zero level (0 ppt). 
Several approaches have been developed for determination of AFM1, but the method of choice is dictated by the type of matrix (fresh, stored, pasteurized milk, liquid or powdered milk, cheese). The methods using enzyme-linked immunosorbent assay (ELISA), thin layer chromatography (TLC) or high performance liquid chromatography (HPLC) were recorded (Mwanza et al., 2015).

This study was aimed to estimate the extent of molds contamination of ultra heat treated (UHT) and powdered flavored milk samples as well as the concentration of AFM1 in the examined samples by ELISA. The ability of the isolated strains to secret mycotoxins was also detected.

\section{MATERIALS AND METHODS}

\section{1) The samples:}

A total of 150 random samples of flavored milk ( 75 for liquid UHT and 75 for powdered form) including banana, strawberry and chocolate (25 samples each) were purchased from different dairy shops and supermarkets in Assiut city, Egypt. The samples were still valid for consumption when purchased. Cartons and packets of the samples were cleaned, thoroughly mixed and aseptically opened. Tenfold serial dilutions were carried out according to APHA (1992). Preparation of the powdered milk samples was proceed according to manufacturing methods by using sterile distilled water.

2) Isolation of molds: was performed according to Baily and Scott (1998).

3) Enumeration of molds: was done according to ISO 6611 (2004) by using malt extract agar (containing $500 \mathrm{mg}$ each of chlortetracycline and HCL chloramphenicol).

4) Identification of the molds: was based on the morphology of the colony, the rate of growth and microscopic morphology according to the morphological description in textbooks dealing with molds (Pitt and Hocking, 2009).

\section{5) Preparation of aflatoxin standard:}

\section{1.) Production and estimation of AFs (Gabal et al., 1994):}

The fungi of A. flavus that were isolated from the examined samples were inoculated into flasks containing $50 \mathrm{ml}$ of sterile yeast extract solution $2 \%$ and sucrose $20 \%$ (YES). The inoculated flasks were incubated at $25{ }^{\circ} \mathrm{C}$ for 15 days, then the flasks content was filtered to separate the mycelial mat from YES medium. At the end of the incubation period, extraction and detection of aflatoxin was estimated by TLC method as recommended by AOAC (1995).

\section{2.) Aflatoxins standard solution for TLC:}

AFs standards B1, B2, G1 and G2 were purchased from Sigma Chemical Company, St. Louis, USA. Resolution of the reference aflatoxin B1, B2, G1 solution were prepared to give final dilution with benzene: acetonitrile (9:1). The same dilution of benzene: acetonitrile $(9: 1)$ was done for the extracted aflatoxins from the isolated A. flavus from the examined samples. A vial of sample extract residue was uncapped and $0.1 \mu \mathrm{l}$ benzene: acetonitrile was added and mixed. The sample solution spot $(5 \mu \mathrm{l})$ was spotted on an imaginary line from the bottom edge of the plate. Standard solution was spotted on the plate with known concentration using $(10-20 \mu \mathrm{l})$ capillary pipette. The plate was developed with toluene: ethyl acetate: formic acid $90 \%(5: 4: 1$, V.V, V) in an equilibrate jar or developing tank for 30 minutes. When the solvent travels about $12 \mathrm{~cm}$ front, the plates were removed from the jar, air dried and inspected under long wave ultraviolet high lamp (360 nm) for examining the tested and standard spots matches.

\section{6) Determination of AFM1:}

The quantitative analysis of AFM1 levels were carried out using a competitive enzyme-linked immunosorbent assay (CELISA) in the examined UHT and powdered milk samples. RIDASCREEN ${ }^{\circledR}$ commercial kit (Art No.: R1121) was used according to ISO 14675 (2003), which most of the reagents used were contained in the RIDASCREEN $^{\circledR}$ test kit. AFM1 standard solutions were at levels of $0,5,10,20$ and 80 ppt.

\section{7) Evaluation of AFM1:}

The mean of the absorbance values obtained for the standards and the samples were divided by the absorbance value of the first standard (zero standards) and multiplied by 100 . The zero standard was thus made equal to $100 \%$ and the absorbance values were quoted in percentages. The absorption was inversely proportional to the AFM1 concentration in the sample. The calibration curve was virtually linear in the $10-80$ ppt range (Fig. 1). According to the test preparation record, the lower detection limit is 5 ppt for milk. Also according to the instructions for use of the RIDASCREEN kit, the recovery rate in spiked milk $(10-80 \mathrm{ppt}$ range) was $95 \%$ with a mean coefficient of variation of $14 \%$. 


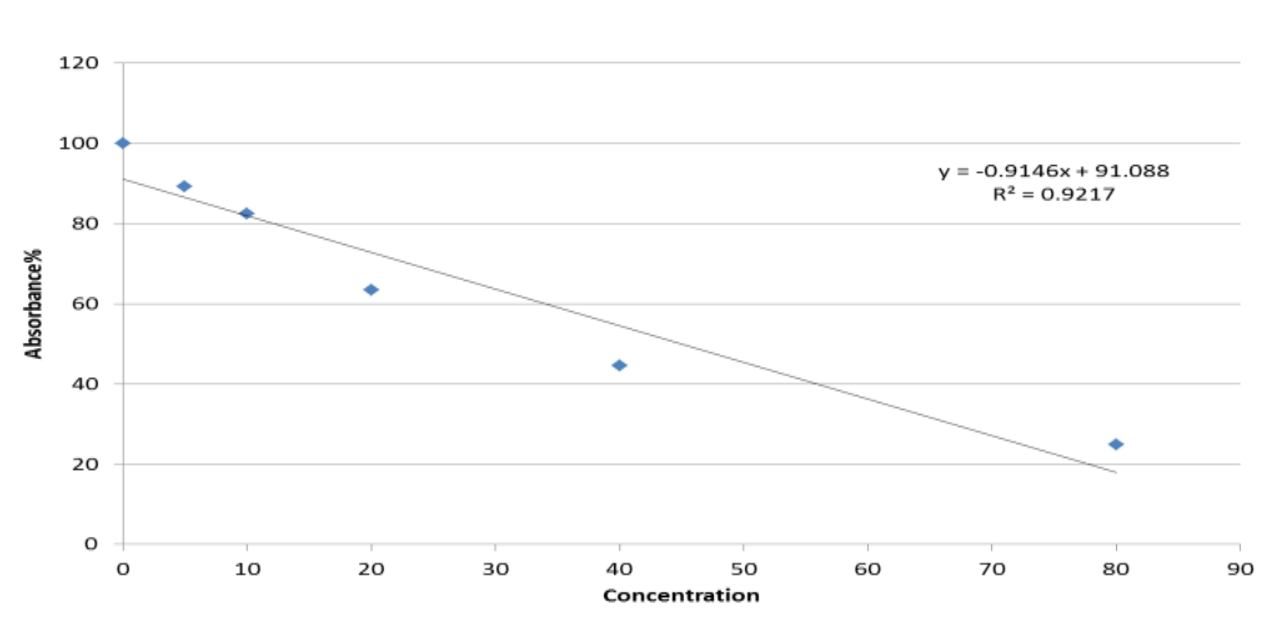

Fig. 1: Standard curve for AFM1 in milk and dairy products samples

\section{RESULTS}

Table 1: Incidence and counts of molds in the examined UHT flavored milk samples.

\begin{tabular}{ccccccc}
\hline \multirow{2}{*}{ The examined types } & \multirow{2}{*}{$\begin{array}{c}\text { The examined } \\
\text { samples no. }\end{array}$} & \multicolumn{5}{c}{ UHT flavored milk } \\
\cline { 3 - 7 } & & Positive samples & \multicolumn{3}{c}{ Count (cfu)/ml } \\
\cline { 3 - 7 } & 25 & 9 & 36 & 10 & 80 & 45 \\
\hline Banana & 25 & 8 & 32 & 10 & 30 & 20 \\
\hline Strawberry & 25 & 25 & 33.33 & 10 & 80 & 28.33 \\
\hline Chocolate & 75 & & & Average \\
\hline Total & & &
\end{tabular}

Table 2: Incidence and counts of molds in the examined powdered flavored milk samples.

\begin{tabular}{ccccccc}
\hline \multirow{2}{*}{ The examined types } & \multirow{2}{*}{$\begin{array}{c}\text { The examined } \\
\text { samples no. }\end{array}$} & \multicolumn{5}{c}{ Powdered flavored milk } \\
\cline { 3 - 7 } & & Positive samples & \multicolumn{3}{c}{ Count (cfu)/ml } \\
\cline { 3 - 7 } & 25 & 8 & 32 & 10 & $1.5 \times 10^{2}$ & 80 \\
\hline Banana & 25 & 11 & 44 & 10 & 40 & 25 \\
\hline Strawberry & 25 & 18 & 72 & 10 & $1.2 \times 10^{2}$ & 65 \\
\hline Chocolate & 75 & 37 & 49.33 & 10 & $1.5 \times 10^{2}$ & 56.67 \\
\hline Total & & & & & &
\end{tabular}

Table 3: Frequency distribution of isolated mold species based on positive samples.

\begin{tabular}{|c|c|c|c|c|c|c|c|c|c|c|}
\hline \multirow{2}{*}{\multicolumn{2}{|c|}{ The isolated mold species }} & \multicolumn{2}{|c|}{$\begin{array}{l}\text { Banana } \\
\text { samples }\end{array}$} & \multicolumn{2}{|c|}{$\begin{array}{c}\text { Strawberry } \\
\text { samples }\end{array}$} & \multicolumn{2}{|c|}{$\begin{array}{c}\text { Chocolate } \\
\text { samples }\end{array}$} & \multicolumn{3}{|c|}{$\begin{array}{c}\text { Total samples } \\
(\mathrm{n}=75 \text { of each })\end{array}$} \\
\hline & & UHT & Powdered & UHT & Powdered & UHT & Powdered & UHT & Powdered & both \\
\hline \multirow{8}{*}{ Aspergillus } & A. flavus & 2 & 4 & 1 & 4 & 2 & 8 & 5 & 16 & 21 \\
\hline & A. niger & 2 & 4 & 5 & 7 & 1 & 12 & 8 & 23 & 31 \\
\hline & A. terreus & 1 & 1 & 2 & 0 & 1 & 3 & 4 & 4 & 8 \\
\hline & A. ustus & 1 & 1 & 0 & 0 & 0 & 0 & 1 & 1 & 2 \\
\hline & A. fumigatus & 1 & 1 & 0 & 0 & 2 & 0 & 3 & 1 & 4 \\
\hline & A. sydwii & 0 & 0 & 1 & 0 & 1 & 0 & 2 & 0 & 2 \\
\hline & A. flavipes & 1 & 0 & 0 & 0 & 0 & 0 & 1 & 0 & 1 \\
\hline & A. ochracious & 1 & 0 & 0 & 0 & 0 & 0 & 1 & 0 & 1 \\
\hline \multirow{6}{*}{ Pencillium } & P. brevicompactum & 2 & 0 & 0 & 0 & 1 & 0 & 3 & 0 & 3 \\
\hline & P. citrinum & 0 & 0 & 0 & 0 & 1 & 0 & 1 & 0 & 1 \\
\hline & P. purpeginum & 0 & 1 & 0 & 0 & 1 & 0 & 1 & 1 & 2 \\
\hline & Alternarea sp. & 0 & 0 & 0 & 0 & 0 & 1 & 0 & 1 & 1 \\
\hline & Cladosporium sp. & 0 & 0 & 0 & 0 & 1 & 0 & 1 & 0 & 1 \\
\hline & Total species & 11 & 12 & 9 & 11 & 11 & 24 & 31 & 47 & 78 \\
\hline
\end{tabular}


Table 4: Incidence of toxogenic strains of $A$. flavus in the examined samples.

\begin{tabular}{cccc}
\hline & & \multicolumn{2}{c}{ Toxogenic A. flavus } \\
\cline { 3 - 4 } Samples types & Total A. flavus isolates & No. & $\%$ \\
\hline UHT milk & 5 & 2 & 40 \\
\hline Powdered milk & 16 & 8 & 50 \\
\hline
\end{tabular}

Table 5: Aflatoxin (B1 \& B2) produced from toxogenic A. flavus (ppb).

\begin{tabular}{cccc}
\hline Aflatoxin type & Min. & Max. & Mean \pm S.E. \\
\hline AFB1 & 0.08 & 1.2 & $0.88 \pm 0.13$ \\
\hline AFB2 & 0.4 & 2 & $1.2 \pm 0.18$ \\
\hline
\end{tabular}

Table 6: Aflatoxin M1 produced from the examined positive samples (ppt).

\begin{tabular}{ccccc}
\hline \multirow{2}{*}{ Samples types } & No. $(\%)$ of the positive & \multicolumn{2}{c}{ Aflatoxin M1(ppt) } \\
\cline { 3 - 5 } & samples & Min. & Max. & Mean \pm S.E. \\
\hline UHT milk & $25(33.33 \%)$ & 1.98 & 2.08 & $2.01 \pm 0.02$ \\
\hline Powdered milk & $37(49.33 \%)$ & 0.97 & 2.22 & $1.72 \pm 0.24$ \\
\hline
\end{tabular}

\section{DISCUSSION}

As shown in Table 1, 33.33\% of the examined UHT flavored milk samples were contaminated by molds. The samples with banana flavor were the highest one as $36 \%$, while for the strawberry and chocolate flavored milk samples were $32 \%$ for each. While, in the examined powdered flavored milk samples 8 out of 25 banana, 11 out of 25 strawberry and 18 out of 25 chocolate, were contaminated with molds in percentages of 32,44 and $72 \%$, respectively, as presented in Table 2 .

Concerning the results showed in Table 3, it was clear that the most common isolated molds from the examined UHT and powdered milk samples were Aspergillus species, followed with other species as Pencillium, Cladosporium and Alternarea. These findings were in agreement with that recorded by Jodral et al. (1993), Garnier et al. (2017), SitiNorashikin et al. (2018). On the other hand, it was in contrast with the results obtained by Gamal et al. (2015) whom recorded the absence of mold in UHT milk.

Aspergillus had the greatest significance as compared to other genera as it is the major toxigenic fungi (D'Mello and Macdonald, 1997) that produces aflatoxins which are the secondary metabolites to the fungi. The hazard of these metabolites comes from their carcinogenic, teratogenic and mutagenic effect (Frisvad et al., 2005).

The presented results in this investigation, declared that $2(40 \%)$ out of 5 and $8(50 \%)$ out 16 strains of A. flavus isolated from UHT and powdered milk samples, respectively, had the ability to produce a variable levels of AFB1 and AFB2 (Tables 4 \& 5). The obtained results were in agreed with that obtained by Ali (2014). AFB1 was found to be the most common and the most hazardous of all mycotoxins found in human food and animal feed. AFB1 was classified as group 1 carcinogens by IARC (2002).

Many scientific papers have been referred to the occurrence of AFM1 in dairy products. Anfossi et al. (2011) demonstrated AFM1 contamination in dairy products in the Middle East.

The current results shown in Table 6 revealed that the concentration of AFM1 in the examined UHT milk samples was ranged from 1.98 to $2.08 \mathrm{ppt}$ with a mean value of $2.01 \pm 0.02 \mathrm{ppt}$. At the meanwhile, the concentration of AFM1 in the examined powdered milk samples was ranged from 0.97 to $2.22 \mathrm{ppt}$ with a mean value of $1.72 \pm 0.28 \mathrm{ppt}$. These recorded values were lower than the maximum tolerance limit $(50 \mathrm{ppt})$ specified in Codex Alimentarius Commissions (2001). These results are coinciding with that recorded by Amer and Ibrahim 
(2010). In contrast, others found a much higher concentration of AFM1 in the examined samples (Shaker and Elsharkawy, 2014). The variations in AFM1 levels between these studies could be attributed to season, environmental conditions, substandard agricultural systems, low availability of green fodder, excessive use of concentrated feed and aflatoxin contamination of feed and grain during storage (Tajkarimi et al., 2007; Rahimi et al., 2010).

The prevention of aflatoxin formation in feeds is very important as the consumption of contaminated feeds by dairy animals causes AFM1 formation in milk. So the easiest and shortest way of reducing AFM1 amount forming in milk to minimum focuses on the prevention of AFB1 formation in feeds. For this, it is necessary to control well the feeds given to dairy animals and to reduce AFB1 amount permitted to take place in feeds to lower levels. In addition, it is considered that food substances should be produced and kept in convenient conditions to prevent aflatoxin formation.

The quality of powdered milk depends not only on the condition of the raw milk, but also on the changes which may take place during manufacture, storage and distribution (Cross, 1997). Milk powder may be subjected to contamination with different species of molds, as they are widely distributed in nature as environmental contaminates of air, water, dust, etc (Amer and Aiad, 2009). Recently, the growing use of the dried milk has made its microbial quality of primary concern due to the high susceptibility of consumers to food-borne diseases.

The present study concluded that the AFM1 levels in the examined samples were being higher than the Egyptian standard regulations, while lower than the maximum tolerance limit specified in European standard.

\section{REFERENCES}

Ali, S.F. (2014): Studies on aflatoxigenic Aspergilli in meat, milk and their products. Ph.D. Thesis, Faculty of Veterinary Medicine, Zagazig University, Department of Bacteriology, Mycology and Immunology, Egypt.

Amer, A.A. and Aiad, A.S. (2009): Occurrence of mycobiota and aflatoxin M1 in some dried dairy products. Assiut Vet. Med. J. 55(123): 100-109.

Amer, A.A. and Ibrahim, M.A. (2010): Determination of aflatoxin M1 in raw milk and traditional cheeses retailed in Egyptian markets. J. Toxicol. Environ. Health Sci., 2: 50-53.

Anfossi, L.; Baggiani, C.; Giovannoli, C. and Giraudi, G. (2011): Occurrence of aflatoxin M1 in dairy products. In: Torres-Pacheco I,
Editor. Aflatoxins-Detection, Measurement and Control. USA: InTech; 2011. ISBN: 978-953-307-711-6. Available from: http:// www.intechopencom/books/aflatoxinsdetectionmeasurement-and-control/ occurrence-of-aflatoxin-m1-in-dairyproducts.

AOAC (Association Official Analytical Chemists) (1995): Official Methods of Analysis. 15 th ed., Assoc. of Official Analytical Chemists, Washington, D. C.

APHA (American Public Health Association) (1992): Standard Method for Examination of Dairy Products. $16^{\text {th }}$ ed. Washington, DC, USA.

Baily, W.R. and Scott, E.G. (1998): Diagnostic Microbiology: A textbook for the isolation and identification of pathogenic Microorganisms. The C.V., Mosby Company Saint Louis.

Bennett, J.W. and Klich, M. (2003): Mycotoxins. Clin. Microbiol. Rev. 16: 497-516.

Bezerra da Rocha, M.E.; da Chagas Oliveira Freire, F.; Erlan Feitosa Maia, F.; Florindo Guedes, M.I. and Rondina, R. (2014): Mycotoxins and their effects on human and animal health. Food Contr., 36, 159-165.

Codex Alimentarius Commissions (2001): Comments submitted on the draft maximum level for Aflatoxin M1 in milk. Codex Committee on Food Additives and Contaminants. $33^{\text {rd }}$ sessions, Hauge, The Netherlands.

Creppy, E.E. (2002): Update of survey, regulation and toxic effect of mycotoxins in Europe. Toxicol. Lett., 127, 19-28.

Cross, S. (1997): Mold spores: the unusual suspects in hay fever. Community Nurse. 3(4): 25-26.

D'Mello, J.P.F. and A.M.C. Macdonald (1997): Mycotoxins. Animal Feed Sci. Tech. 69: 155-166.

Egyptian Regulations (1990): Maximum Limits for Mycotoxin in Foods. Part L Aflatoxins E.S.1875-1990. Egyptian Organization for Standardization and Quality Control (EOSQC), 1990.

Frisvad, J.C.; Skouboe, P. and Samson, R.A. (2005): Taxonomic comparison of three different groups of aflatoxin producers and a new efficient producer of aflatoxin B1, sterigmatocystin and 3-Omethylsterigmatocystin, Aspergillus rambellii sp. nov. Syst. Appl. Microbiol., 28: 442-453.

Gabal, M.A.; Hegazi, S.M. and Hassamien, Y. (1994): Aflatoxin production by Aspergillus flavus field isolates. Vet. Human Toxicol., 36: 519-521.

Gamal, M.H.; Arafa, M.S.; Meshref and Soad, M.G. (2015): Microbiological quality and safety of fluid milk marketed in Cairo and Giza 
Governorates. Current Res. in Dairy Sci., 7: 18-25.

Garnier, L.; Valence, F.; Pawtowski, A.; Auhustsinava-Galerne, L.; Frotté, N.; Baroncelli, R.; Deniel, F.; Coton, E. and Mounier, J. (2017): Diversity of spoilage fungi associated with French dairy products. Int. J. Food Microbiol., 241: 191-197.

Gürbay, A.; Aydin, S.; Girgin, G.; Engin, A.B. and Sahin, G. (2006): Assessment of aflatoxin M1 levels in milk in Ankara, Turkey. Food Cont., 17: 1-4.

IARC (International Agency for Research on Cancer) (2002): Some traditional herbal medicines, some mycotoxins, naphthalene and styrene. Summary of data reported and evaluation. IARC Monographs on the Evaluation of the Carcinogenic Risk to Humans. International Agency for Research on Cancer, Lyon, France, 82.

ISO 14675 (2003): Milk and Milk Product Guidelines for a Standardized Description of Competitive Enzyme Immunoassay. Determination of Aflatoxin M1. International Organization for Standardization, Geneva, Switzerland.

ISO 6611 (2004): Milk and Milk ProductsEnumeration of colony forming units of yeasts and /or moulds- colony- count technique at 25 degrees C. International Organization for Standardization, Geneva, Switzerland

Jodral, M.; Liñan, E.; Acosta, I.; Gallego, C.; Roja, F. and Bentabol, A. (1993): Mycoflora and toxigenic Aspergillus flavus in Spanish milks. Int. J. Food Microbiol., 36: 171-174.

Kure, C.F.; Skaar, I. and Brendehaug, J. (2004):

Mould contamination in production of semi- hard cheese. Int. J. Food Microbiol., 93: 4149.

Mwanza, M.; Abdel-Hadi, A.; Ali, A.M. and Egbuta, M. (2015): Evaluation of analytical assays efficiency to detect aflatoxin M1 in milk from selected areas in Egypt and South Africa. J. Dairy Sci., 98: 6660-6667.

Pal, M. (2014): Spoilage of dairy products due to fungi. Beverage \& Food World-41-7, 37-40.

Pitt, J.I. and Hocking, A.D. (2009): Fungi and Food Spoilage Book. $4^{\text {th }}$ ed., Chapter 4-10, pp. 29. Academic Press, New York, London.

Rahimi, E.; Bonyadian, M.; Rafei, M. and Kazemeini, H.R. (2010): Occurrence of aflatoxin M1 in raw milk of five dairy species in Ahvaz, Iran. Food Chem. Toxicol., 48:129-31.

Shaker, E.M. and Elsharkawy, E.E. (2014): Occurrence and the level of contamination of aflatoxin M1 in raw, pasteurized, and ultra-heat treated buffalo milk consumed in Sohag and Assiut, upper Egypt. J. Environ. Occup. Sci. 3(3):136-140.

SitiNorashikin, A.; Nor-Khaizura, M.A.R. and Wan Zunairah, W.I. (2018): Microbiological quality and safety of unfinished UHT milk at storage time- temperature abuse. Int. J. Curr. Microbiol. Appl. Sci., 7(3): 22782296.

Suriyarachchi, V.R. and Fleet, G.H. (1981): Occurrence and growth of yeasts in yoghurts. Appl. Environ. Microbiol., 42(4): 574-579.

Tajkarimi, M.; ShojaeeAliabadi, F.; SalahNejad, M.; Pursoltani, H.; Motallebi, A.A. and Mahdavi, H. (2007): Seasonal study of aflatoxin M1 contamination in milk in five regions in Iran. Int. J. Food Microbiol. 116: 346-9.

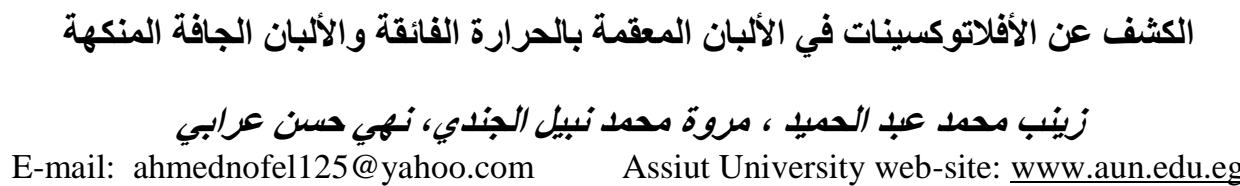

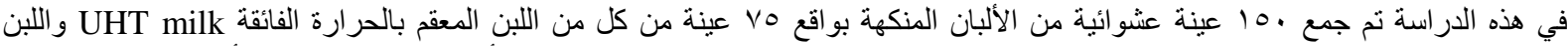

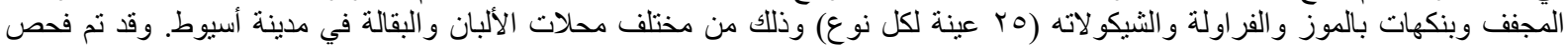

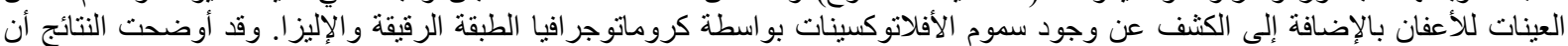

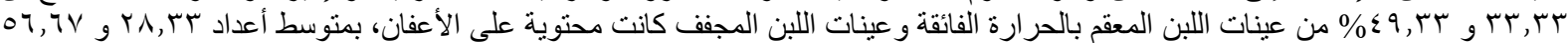

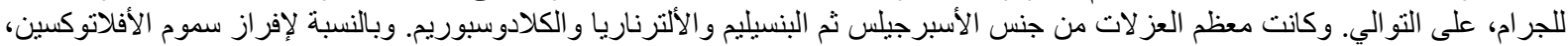

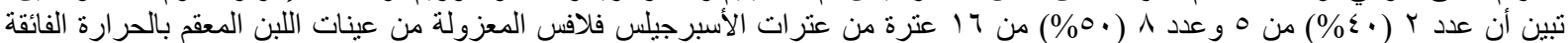

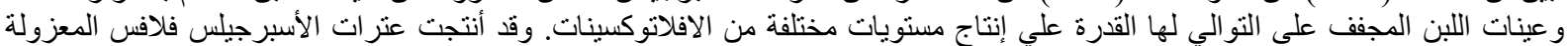

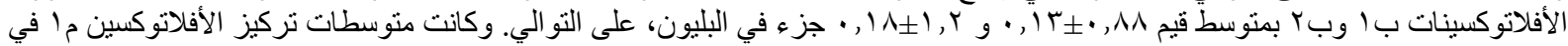

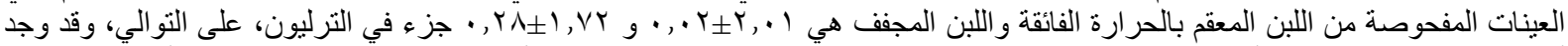

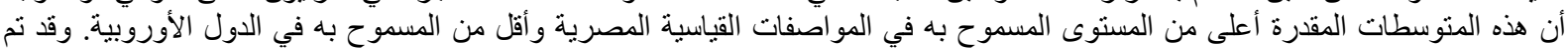

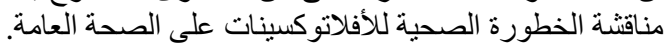
الكلمات الكاشفة: الألبان المنكهة، الفطريات، الأفلاتوكسينات 